1Jagiellonian University of Kraków, Collegium Medicum, Kraków, Poland

${ }^{2}$ The University Hospital in Kraków, Department of Metabolic Diseases, Kraków, Poland

${ }^{3}$ Medical University of Lodz, Department of Internal Medicine and Diabetology, Lodz, Poland

${ }^{4}$ Poznań University of Medical Sciences Division of Reproduction, Poznań, Poland

${ }^{5}$ Medtronic, Warsaw, Poland

${ }^{6}$ Medtronic, Tolochenaz, Switzerland

${ }^{7}$ Medtronic, Northridge, California, USA

\title{
Objectives and methods of the ORCHESTRA FOUNDATION Registry study: a multicenter observational study of the use of insulin pump therapy in pregnant women with type 1 diabetes mellitus in Poland
}

\section{ABSTRACT}

Background. The ORCHESTRA FOUNDATION Registry study was a prospective, multicenter, observational, post-market study investigating the use of an insulin pump with or without continuous glucose monitoring (CGM) [i.e., sensor-augmented pump (SAP) or sensor-integrated insulin pump (SIP)]; before, during, and after pregnancy, in women with type 1 diabetes mellitus (T1DM).

Methods. Study participants enrolled in $\mathbf{2 4}$ centers, in Poland, and contributed intake and follow-up data for up to 22 months (i.e., up to 12 months pre-conception, throughout pregnancy, and 6 weeks after delivery). Participants who were already pregnant were enrolled up to the 16th week of pregnancy. Investigated outcomes included $\mathrm{HbA}_{1 \mathrm{c}}$ before and during pregnancy, and serious adverse events (e.g., severe hypoglycemia, diabetic ketoacidosis, miscarriage, and hospitalization due to

Address for correspondence:

prof. dr hab. n. med. Jacek Sieradzki

Collegium Medicum

Uniwersytet Jagielloński w Krakowie

e-mail: ja.sieradzki@gmail.com

Clinical Diabetology 2018, 7, 3, 136-144

DOI: $10.5603 /$ DK.2018.0009

Received: 17.01.2018

Accepted: 26.02.2018 any bleeding or any symptoms suggesting premature delivery). Routine clinical data including maternal weight, body mass index, and daily insulin use were also recorded. The insulin delivery devices used in the study were the MiniMed ${ }^{\mathrm{TM}}$ Paradigm $^{\mathrm{TM}}$ REAL-Time insulin pump with CGM (via the MiniMed Sof-sensor ${ }^{\mathrm{TM}}$ sensor) or without CGM, and the MiniMed Paradigm Veo $^{\mathrm{TM}}$ with CGM (via the Enlite ${ }^{\mathrm{TM}}$ sensor).

Results. Study enrollment began in May 2013 and the last patient completed the study in August 2017. Conclusions. The ORCHESTRA FOUNDATION Registry study provides an opportunity to assess the effects of automated insulin delivery in pregnant women with T1DM using insulin pumps with or without continuous glucose monitoring. (Clin Diabetol 2018; 7, 3: 136-144)

Key words: type 1 diabetes, continuous subcutaneous insulin infusion, pregnancy, registry study, sensor-augmented pump therapy; sensor-integrated pump therapy

\section{Introduction}

Diabetes is the most common metabolic disease complicating pregnancy, and the number of pregnancies complicated by diabetes is rising as the number of people with diabetes increases. Diabetes during 
pregnancy is associated with considerable risks for both the mother and the fetus. Risks for the mother include miscarriage, hypoglycemia, ketoacidosis, preeclampsia, polyhydramnios, and premature or obstructed labor, which may necessitate caesarean section. Fetuses and neonates are at increased risk of congenital malformations, perinatal mortality, birth injuries, macrosomia, neonatal hypoglycemia, jaundice, and respiratory distress [1-8].

The relationship between glucose control before conception and the incidence of miscarriage and congenital malformations is well established $[6,9,10]$. High $\mathrm{HbA}_{1 \mathrm{c}}$ levels in early pregnancy are associated with complications such as congenital malformations and miscarriage, while hyperglycemia in late pregnancy is associated with macrosomia leading to birth injury and caesarean section, other fetal morbidity [1, 1-5, 8-11], and a potential predisposition to type 2 diabetes and obesity $[12,13]$.

Tight glucose control $\left(\mathrm{HbA}_{1 \mathrm{c}}<6.0 \%\right)$ during pregnancy is recommended by many guidelines $[7,14,15]$, but achieving such control is challenging. It is crucial to achieve near-normal glycemic control before and during pregnancy, and to mimic the patterns of glucose levels seen in normal pregnancies. However, women with type 1 diabetes mellitus (T1DM) treated with multiple daily injections (MDI) throughout pregnancy experience prolonged daily exposure to higher than recommended glucose levels, resulting in a 3-5-fold greater incidence of complications than that observed in the general population [11]. Some studies have shown that improvements in $\mathrm{HbA}_{1 \mathrm{c}}$ levels achieved with MDI are associated with an increased risk of severe hypoglycemia, particularly nocturnal and undetected postprandial hyperglycemia [16-18]. Severe hypoglycemia affects $25-40 \%$ of pregnant women and is $3-5$ times more common in early pregnancy than in the period before pregnancy $[18,19]$. In one study, intensively treated pregnant women were 15 times more likely to experience severe hypoglycemia than women receiving conventional treatment [18]. During the first trimester of pregnancy, nocturnal hypoglycemia may be present in as many as $37 \%$ of pregnant women [20]. Although hypoglycemia is more harmful to the mother than to the fetus, hyperglycemia after episodes of hypoglycemia and variable levels of glycemia may also be dangerous for the fetus [20-22].

In non-pregnant women with T1DM, continuous subcutaneous insulin infusion (CSII) has been shown to be associated with a reduced rate of severe hypoglycemia, compared with MDI therapy, without adversely affecting glycemic control [22]. Similarly, insulin pump use in pregnancy has been found to reduce $\mathrm{HbA}_{1 \mathrm{c}}$ levels in patients with T1DM without increasing the rate of severe hypoglycemia or ketoacidosis [23]. Both CSII and continuous glucose monitoring (CGM), alone or in combination as a sensor-augmented pump (SAP) or sensor-integrated pump (SIP) therapy, improve glycemic control by reducing $\mathrm{HbA}_{1 \mathrm{c}}$ from $0.4-1.2 \%$ [24-30]. The recent INTERPRET study, the largest and longest multicenter prospective study to date, has confirmed the effectiveness of CGM in pump users; data from 263 patients using SAP therapy under real-life conditions over 12 months revealed significantly lower rates of hospitalization, greater treatment satisfaction, and reduced fear of hypoglycemia compared to CGM nonusers [31]. Other studies have also shown that the use of CGM and related features such as alarms and automatic insulin suspension (i.e., low glucose suspension [LGS]) reduces fear of hypoglycemia, the incidence of severe hypoglycemic events, and time spent in hypoglycemia [32-35]. More importantly, the use of the LGS feature does not result in rebound hyperglycemia [33].

While the frequency, magnitude, and duration of hyperglycemia or its link with prior hypoglycemia, are best captured by CGM, self-management of glycemia is essential for good glycemic control in diabetic patients. Postprandial glucose levels during pregnancy show a strong association with the incidence of macrosomia [36]; and postprandial glucose monitoring and maintained glycemic targets have been shown to improve neonatal outcomes better than preprandial glucose monitoring [7]. Neonatal outcomes are more closely associated with hyperglycemic excursions, versus average daily glycemic control $[37,38]$. Hence, the ability to analyze hypoglycemia and hyperglycemia with CGM may be useful in detecting anticipated neonatal outcomes.

In summary, pump therapy, particularly that involving use of SAP or SIP systems, provides the technology to facilitate reduction of $\mathrm{HbA}_{1 \mathrm{c}}$ before and during pregnancy. Such therapy can alert the mother to glucose excursions, and assist in preventing severe hypoglycemic events without incurring the risk of rebound hyperglycemia. For this reason, the Orchestra Foundation (Wielka Orkiestra Świątecznej Pomocy) funded the ORCHESTRA Registry study, to determine effectiveness of CSII therapy with and without CGM in pregnant women, in Poland. The design and methodology of this study are described in this paper.

\section{Research design and methods}

The study protocol was approved by Central Ethics Committee, and was valid for all participating centers. No Competent Authority approval was required for observational studies in Poland. 


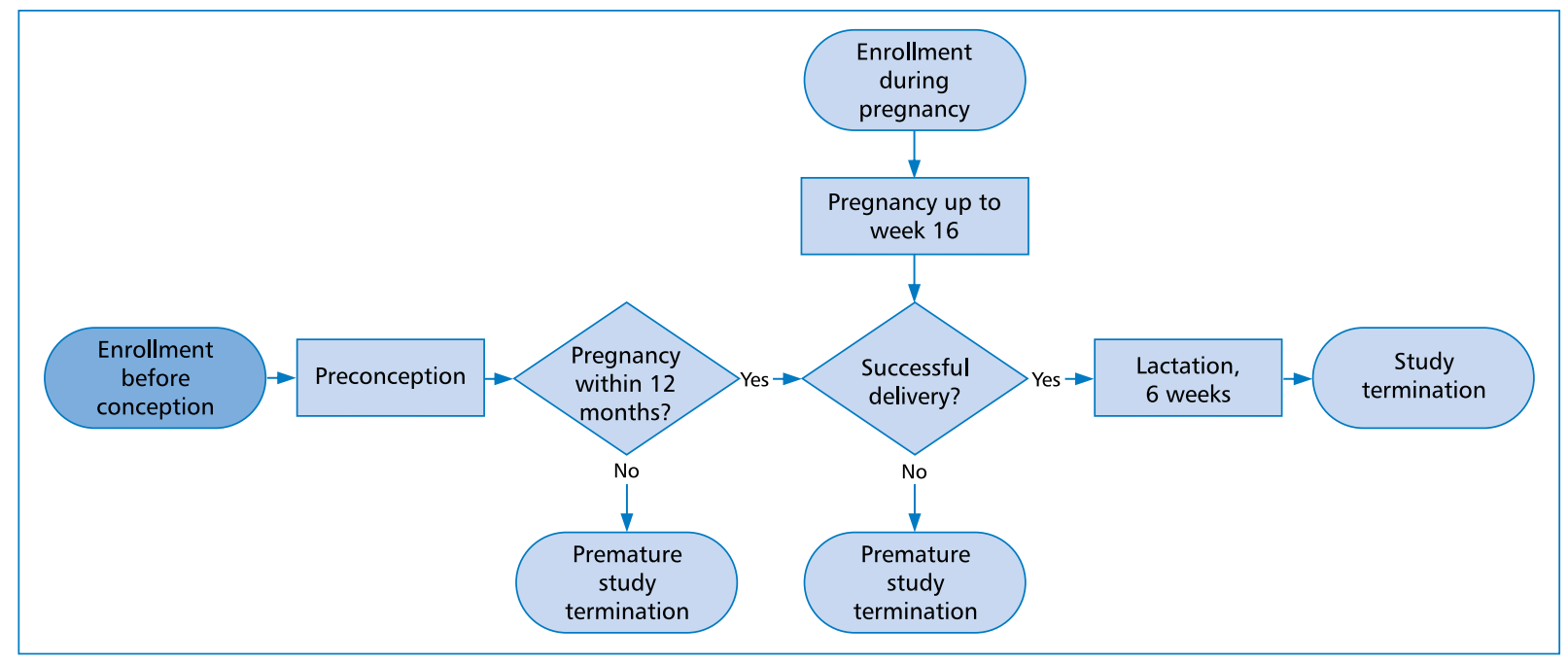

Figure 1. Study enrollment and termination procedures

\section{Investigators and study duration}

In total, 24 centers in Poland, identified by the Orchestra Foundation, participated in the study (See Supplemental Material). Enrollment began in May 2013, the last patient completed the study in August 2017, and data analysis has been completed in February 2018.

\section{Study design and objectives}

The study was a national, prospective, multicenter, observational, post-market study of the effectiveness of commercially available devices [i.e., the MiniMed Paradigm REAL-Time insulin pump system (CSII with or without (GM); and the MiniMed Paradigm Veo insulin pump system with the Enlite ${ }^{\mathrm{TM}}$ sensor] (Medtronic, Poland). The primary objective was to assess the benefits of CSII and SAP on maternal glycemic control $\left(\mathrm{HbA}_{1 \mathrm{c}}\right.$ and CGM data). Secondary objectives were: 1) to assess the prevalence of pregnancy complications (e.g., preterm delivery, low infant birth weight, neonatal care admissions) throughout pregnancy, during delivery, and during lactation for up to 6 weeks after delivery; 2) to evaluate the potential benefits of CSII and SAP on neonatal outcomes; and 3) to evaluate changes in patient-reported outcomes, such as concerns about hypoglycemia and satisfaction with diabetes treatment.

\section{Study population}

The study population consisted of women aged 18-45 years with T1DM who either intended to become pregnant within 12 months or were already in the early stages of pregnancy ( $\leq 16$ weeks). Women were eligible for inclusion in the study if they had been treated with MDI for, at least, 3 months and had indications for
CSII, SAP or SIP. Women with type 2 diabetes, gestational diabetes or maturity-onset diabetes of the young (MODY) were excluded, as were patients using insulin pumps that had not been donated by the Orchestra Foundation. Women who required assisted fertilization technologies, or participated in any interventional clinical trial within 3 months prior to screening, were also excluded. Written informed consent was obtained from all patients before enrollment in the study.

Based on local data and experience, it was anticipated that in about two thirds of cases CSII would start during the first trimester of pregnancy ( $\leq 16$ weeks). The estimated total sample size was 500 women, which included 100 with complete follow-up (from preconception until 6 weeks post-delivery), 300 enrolled up to the 16th week of pregnancy, and 100 who may be expected to be withdrawn for various reasons. Enrollment would stop when data from 100 participants with complete follow-up from pre-conception until 6 weeks post-delivery had been collected. A flow chart summarizing enrollment and termination procedures is shown in Figure 1.

\section{Pre-conception care}

There were 24 specialized centers in Poland with professional health care teams consisting of: a diabetologist, diabetes educator, nurse, and dietitian. All women with T1DM participating in the pregnancy planning program received intensive diabetes management in these clinics. The intensive diabetes management involved education on diet and carbohydrate counting, physical activity, folic acid supplementation, glycemic goals, self-monitoring of blood glucose (SMBG), and self-adjusting insulin dose. Care included frequent 
outpatient visits, and hospitalization if necessary. All women were trained by a dietician and/or diabetes educator. The recommended standard caloric intake was $35 \mathrm{kcal} / \mathrm{kg}$ of body weight, of which $40-50 \%$ was to be covered by carbohydrates, $20-30 \%$ by fats, and $30 \%$ by proteins. Excessive weight gain was addressed by reducing daily food intake accompanied by a regular daily self-assessment of urine ketones. According to the Polish Diabetes Association recommendations in year 2015 [15], the therapeutic targets for all women planning a pregnancy or who are pregnant are: a) $\mathrm{HbA}_{1 \mathrm{c}}$ $<6.1 \%$, b) fasting SMBG within $60-90 \mathrm{mg} / \mathrm{dl}$, and c) subsequent pre- and 1-hour postprandial SMBG within 60-120 mg/dl. The Association also recommends that all women planning a pregnancy receive a supplementation of folic acid. The glycaemia monitoring plan was highly structured, in terms of both timing and frequency, and was provided to all women by the diabetes educator. Women were requested to wear a CGM system or to perform SMBG 8 to 10 times a day using a blood glucose meter transmitting to an insulin pump: fasting, before, and one hour after main meals, at bedtime, and between 2-4 am.

\section{Study procedures}

Study visits and procedures are summarized in Table 1. All women had an initial pre-conception visit, with a second visit $12 \pm 4$ weeks after amenorrhea. Women who did not conceive within 12 months of the initial visit had a third visit at 12 months \pm 2 weeks. Women who were already pregnant at enrollment had the initial visit at the time of enrollment. All pregnant women were assessed after 24 and 36 weeks ( \pm 2 weeks) of amenorrhea, at delivery, and 6 weeks after delivery (both \pm 2 weeks). At each assessment, clinical data were recorded in electronic case report forms (eCRFs), and data from devices (pumps and glucose meters) were uploaded into CareLink ${ }^{\mathrm{TM}}$ Clinical software. Women who experienced a miscarriage kept their pump for an additional 3 months after the miscarriage, if they wished to continue insulin pump therapy.

A CareLink USB was provided for uploading blood glucose meter or insulin pump data to CareLink Clinical software. In addition, a blood glucose meter compatible with the CareLink Clinical software; insulin pump therapy consumables; and all necessary devices for insertion were provided. Except for the Enlite sensors, which are single-use devices, all devices were loaned to the study participants for the entire study period, after which they would be returned to the center investigators.

Approximately two thirds of the participants had been provided the Paradigm REAL-Time pump, and the remaining were provided the Paradigm Veo pump. The participants using the Paradigm REAL-Time system could use CGM (i.e., the MiniLink ${ }^{\mathrm{TM}}$ transmitter and Sof-Sensor sensor) at their own expense, if the HCP agreed to this. The participants using the Paradigm Veo received as many Enlite sensors free of charge as their health care professional (HCP) considered necessary. All participants received adequate training using a standardized training checklist on the use of insulin pumps, CGM, and consumables. This training was provided by the HCP at the investigation center, or a Certified Product Trainer, based on local practice. All participants were to have shown good compliance with, and an ability to understand and use, their therapy, as assessed by the treating physician.

\section{Data recorded}

\section{Clinical outcomes}

Maternal $\mathrm{HbA}_{1 \mathrm{c}}$ levels before the initiation of insulin pump therapy were obtained retrospectively from medical records. $\mathrm{HbA}_{1 \mathrm{c}}$ was measured on 2-3 occasions during pregnancy, with a final measurement being made at the end of the study. Other clinical data collected included weight, BMI, daily insulin use, the number of SMBG measurements conducted per day (or self-reported by the participant), and the incidence of serious adverse events (e.g., severe hypoglycemia, diabetic ketoacidosis, miscarriage, hospitalizations). Concerns about hypoglycemia were assessed using the Hypoglycemia Fear Survey (HFS) at enrollment, on 2-3 occasions during pregnancy, and 6 weeks after delivery. Satisfaction with diabetes treatment was assessed by means of the Diabetes Treatment Satisfaction Questionnaire (DTSQ) at the aforementioned occasions, and the DTSQc at pregnancy week 24 [39, 40]. Data on sensor and pump use during delivery, satisfaction with treatment during delivery, and additional participantreported outcomes were also recorded.

The following neonatal outcomes were recorded: incidence rates of mode of delivery (e.g., i.e., normal, elective, cesarean section (CS), and emergency CS), gestational age at delivery, infant birth weight percentile [Large for Gestational Age (LGA), small for gestational age (SGA)], neonatal care admission, neonatal morbidity, pregnancy-related serious adverse events, and feeding status on discharge from hospital.

\section{Adverse events}

Serious adverse events were defined as: a) events leading to death; b) events leading to life-threatening illness or injury, permanent anatomical or functional impairment, or in-patient or prolonged hospitalization 


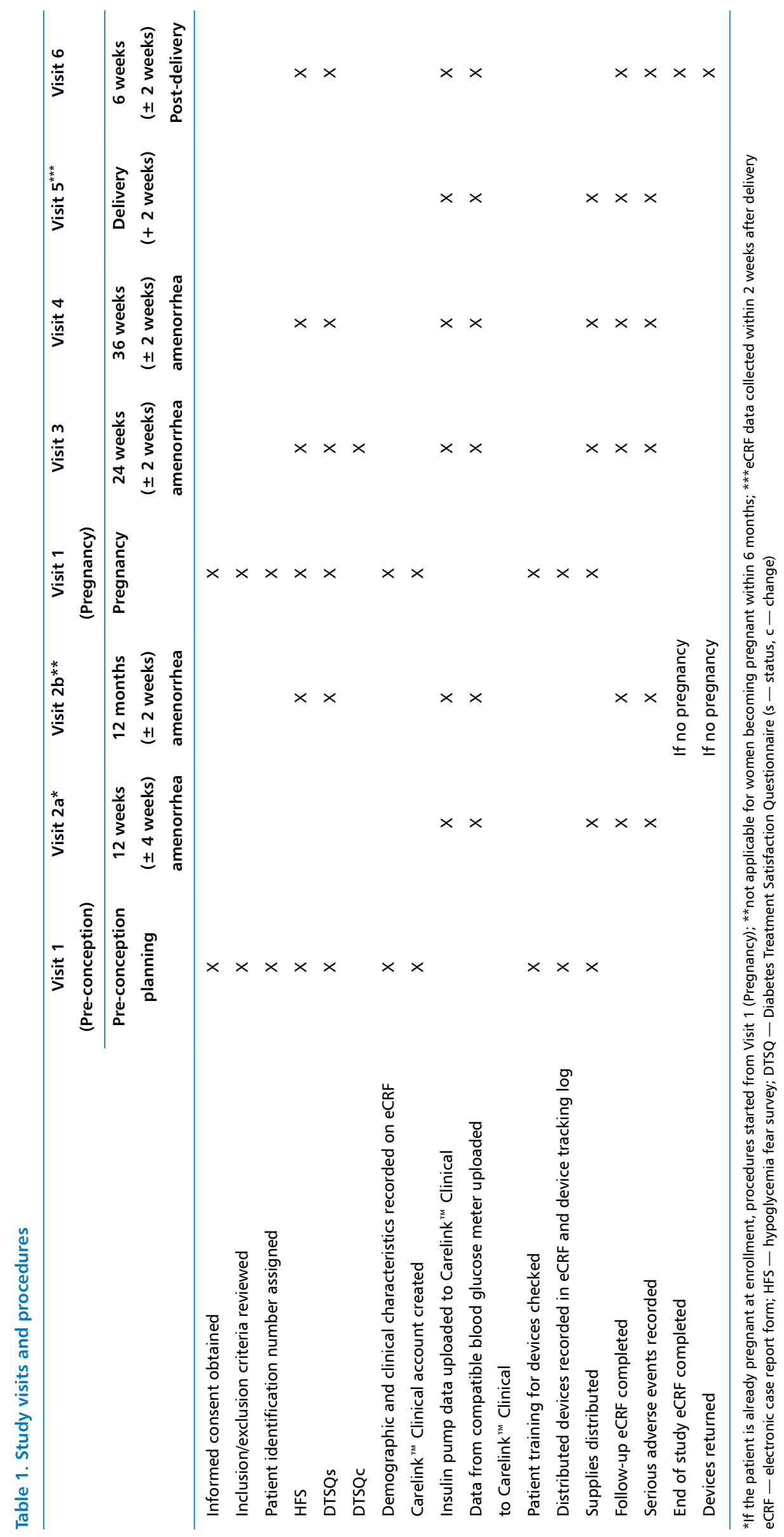


or medical or surgical intervention (particularly hypoglycemia or hyperglycemia); and c) events leading to fetal distress, fetal death or congenital abnormalities or birth defects. Potential device-related adverse events included: skin reactions to infusion set or sensor adhesive, inflammation or bruising at the insulin infusion site, or incorrect insulin delivery.

\section{Statistical methods and analysis}

All enrolled subjects who have participated in Orchestra Pregnancy Observational Study in Poland were included in the efficacy and safety analysis. Baseline information and demographic characteristics such as age, gender, weight, BMI, diabetes duration, insulin regimen, etc. were summarized. Medical information such as previous severe hypoglycemia and DKA history up to 12 months prior to study start was also summarized.

Clinical and safety data were summarized using descriptive statistics for all available groups: 1) all enrolled; 2) those who failed to achieve a pregnancy; 3 ) those who become pregnant after the pre-conception phase; 4) those already pregnant at enrollment.

The primary analysis investigated the change in $\mathrm{HbA}_{1 \mathrm{c}}$ from the beginning to the end of pregnancy. Secondary analyses included the following: the proportion of subjects achieving $\mathrm{HbA}_{1 \mathrm{c}}<6 \%, 6.5 \%, 7 \%, 7.5 \%$, and $8 \%$; descriptive statistics for sensor glucose (e.g., mean, variability, percent in range and AUC) analyzed as overall and stratified by pregnancy outcome (no conception, delivery, miscarriage, etc.); and completeness of treatment phase (i.e., complete follow-up, pregnancy and 6 weeks after delivery, pre-conception phase only, etc.).

Other maternal outcomes, such as weight, BMI, daily insulin requirements (units) at the moment of the visit, and microalbumin excretion with albumin/ /creatinine ratio were also collected.

Initial results after completed recrutation are shown in Figure 2.

\section{Discussion}

Insulin pump therapy has been shown to improve quality of life in pregnant women with diabetes [31, 41]. The Orchestra Foundation facilitated use of insulin pumps by all pregnant women with type 1 diabetes in Poland; hence, all participants fulfilling study inclusion criteria were registered, and only those with contraindications to insulin pump therapy were excluded from the study. The clinical study intended to recruit as many women as possible during the pre-conception period: approximately 20-30\% participation was anticipated.

The advantage of this study design was the use of insulin delivery devices with the same platform by all participants. All studied women were Caucasian with T1DM. All study centers used the same devices and the same methods of education and training for participants. However, a limitation was that, although studies comparing the use of CSII and MDI have yielded inconsistent results [23, 29,42-46], it was not possible to compare the results of pump use with a control group not using pump therapy and/or pump therapy supported by CGM. Nevertheless, this study offered a unique opportunity to follow a large patient population using standardized insulin-delivery devices to assess the prevalence of pregnancy complications and outcomes. It was also possible to compare the results of introducing pump therapy, with or without CGM, before and during pregnancy.

\section{Author disclosure statement}

$\mathrm{JS}^{1}$ reports receiving lecturing and consulting fees from MSD, Bioton, Novartis, Medtronic, and Mylan; and has conducted clinical trials as co-investigator for Medtronic.

$\mathrm{KC}^{2}$ has provided advisory services to Medtronic and Roche; attended conferences organized by Eli-Lilly \& Company, Novo Nordisk, Roche, and Medtronic, as lecturer or contributor; reports receiving lecturing and consulting fees from Medtronic, Roche, and Novo Nordisk; and has conducted clinical trials as co-investigator for GlaxoSmithKline.

$\mathrm{KC}^{3}$ has conducted clinical trials as co-investigator for Medtronic, Eli-Lilly \& Company, Novo Nordisk A/S, AstraZeneca $A B$, Boehringer Ingelheim, and Pfizer; provided advisory services to Medtronic, Eli-Lilly \& Company, Novo Nordisk A/S; attended conferences organized by Eli-Lilly \& Company, Novo Nordisk, and Medtronic as contributor; and reports receiving lecturing and consulting fees from Medtronic, Bayer AG, Eli Lilly \& Company, Novo Nordisk A/S, Sanofi-Aventis, Boehringer Ingelheim, and Johnson\&Johnson Sp. z o.o.

EW-O 4 has conducted clinical trials as co-investigator for Medtronic and Novo Nordisk; provided advisory services to Medtronic, Eli-Lilly \& Company, and Novo Nordisk; attended conferences organized by Novo Nordisk, Eli-Lilly \& Company, and Medtronic as contributor; and received investigator fees in relation to lectures and study protocols.

$\mathrm{KS}, \mathrm{SR}$, and $\mathrm{JS}^{7}$ are employees of Medtronic.

\section{Acknowledgements}

We thank the Orchestra Foundation (WOŚP) for donating the devices to the investigational sites and giving access to pump therapy and medical follow up to women in Poland who were pregnant or planning a pregnancy. We thank the ORCHESTRA study team at Medtronic for their support, in addition to the moni- 


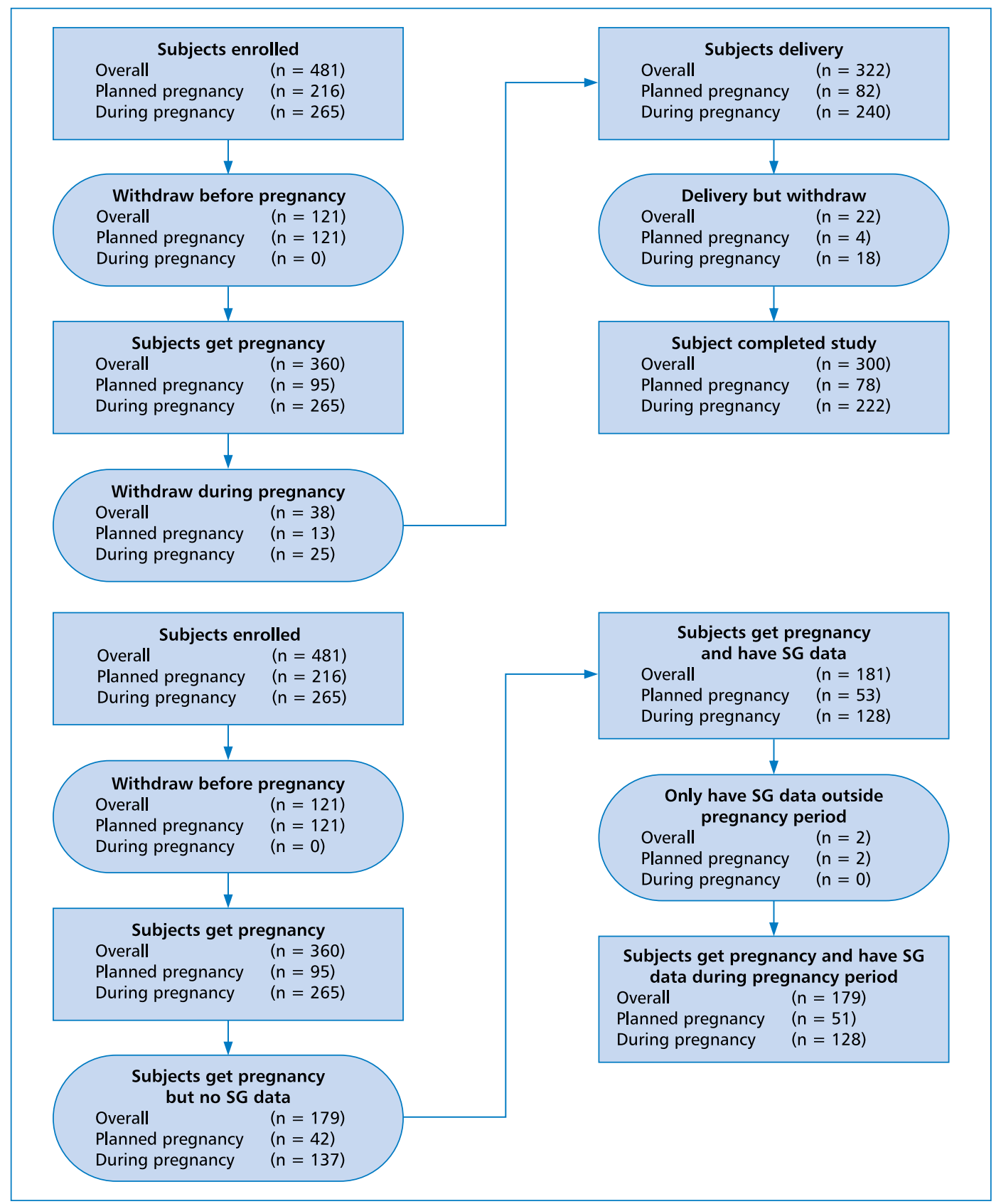

Figure 2. Initial data after completed recrutation

tors, investigators, study coordinators, and patients during this trial. We also thank Anna Sadowska-Segit and Attila Detary, employees of Medtronic, for their assistance throughout the conduct of the study. Editorial assistance in the preparation of this paper was provided by Dr. Michael Shaw (MScript Ltd, Hove, UK) and medical writing assistance was provided by Dr. Toni L. Cordero (Medtronic, Northridge, CA, USA).

Clinicaltrials.gov identifier: NCT01779141

\section{REFERENCES}

1. Evers IM, de Valk HW, Visser GHA. Risk of complications of pregnancy in women with type 1 diabetes: nationwide prospective study in the Netherlands. BMJ. 2004; 328(7445): 915, doi: 10.1136/bmj.38043.583160.EE, indexed in Pubmed: 15066886.

2. Boulot $P$, Chabbert-Buffet N, d'Ercole C, et al. Diabetes and Pregnancy Group, France. French multicentric survey of outcome of pregnancy in women with pregestational diabetes. Diabetes Care. 2003; 26(11): 2990-2993, doi: 10.2337/diacare.26.11.2990, indexed in Pubmed: 14578228.

3. Jensen DM, Damm P, Moelsted-Pedersen L, et al. Outcomes in type 1 diabetic pregnancies: a nationwide, population-based 
study. Diabetes Care. 2004; 27(12): 2819-2823, doi: 10.2337/ /diacare.27.12.2819, indexed in Pubmed: 15562191.

4. Lauenborg J, Mathiesen E, Ovesen P, et al. Audit on stillbirths in women with pregestational type 1 diabetes. Diabetes Care. 2003; 26(5): 1385-1389, doi: 10.2337/diacare.26.5.1385, indexed in Pubmed: 12716793.

5. Penney G, Mair G, Pearson D, et al. Scottish Diabetes in Pregnancy Group. Outcomes of pregnancies in women with type 1 diabetes in Scotland: a national population-based study. BJOG. 2003; 110(3): 315-318, doi: 10.1046/j.1471-0528.2003.02067.x, indexed in Pubmed: 12628275.

6. Tennant PWG, Glinianaia SV, Bilous RW, et al. Pre-existing diabetes, maternal glycated haemoglobin, and the risks of fetal and infant death: a population-based study. Diabetologia. 2014; 57(2): 285-294, doi: 10.1007/s00125-013-3108-5, indexed in Pubmed: 24292565.

7. National Institute for Health and Care Excellence (NICE): Diabetes in pregnancy: management of diabetes and its complications from preconception to the postnatal period. NICE Guideline NG3, February 2015. Nice.org.uk/guidance/ng3 (Accessed 9 February 2016).

8. Persson M, Norman M, Hanson U. Obstetric and perinatal outcomes in type 1 diabetic pregnancies: A large, population-based study. Diabetes Care. 2009; 32(11): 2005-2009, doi: 10.2337/ /dc09-0656, indexed in Pubmed: 19675195.

9. Ekbom P, Damm P, Feldt-Rasmussen Bo, et al. Elevated thirdtrimester haemoglobin A 1c predicts preterm delivery in type 1 diabetes. J Diabetes Complications. 2008; 22(5): 297-302, doi: 10.1016/j.jdiacomp.2007.03.008, indexed in Pubmed: 18413167.

10. Jensen DM, Korsholm L, Ovesen $P$, et al. Peri-conceptional A1C and risk of serious adverse pregnancy outcome in 933 women with type 1 diabetes. Diabetes Care. 2009; 32(6): 1046-1048, doi: 10.2337/dc08-2061, indexed in Pubmed: 19265024.

11. Macintosh MCM, Fleming KM, Bailey JA, et al. Perinatal mortality and congenital anomalies in babies of women with type 1 or type 2 diabetes in England, Wales, and Northern Ireland: population based study. BMJ. 2006; 333(7560): 177, doi: 10.1136/ /bmj.38856.692986.AE, indexed in Pubmed: 16782722.

12. Clausen TD, Mathiesen ER, Hansen $T$, et al. High prevalence of type 2 diabetes and pre-diabetes in adult offspring of women with gestational diabetes mellitus or type 1 diabetes: the role of intrauterine hyperglycemia. Diabetes Care. 2008; 31(2): 340-346, doi: 10.2337/dc07-1596, indexed in Pubmed: 18000174.

13. Weiss PA, Scholz HS, Haas J, et al. Long-term follow-up of infants of mothers with type 1 diabetes: evidence for hereditary and nonhereditary transmission of diabetes and precursors. Diabetes Care. 2000; 23(7): 905-911, doi: 10.2337/diacare.23.7.905, indexed in Pubmed: 10895839.

14. American Diabetes Association: Standards of medical care in diabetes - 2015. Diabetes Care. 2015; 38(suppl 1).

15. Polish Diabetes Association: The clinical guidelines for the proceeding with patient with diabetes 2015 (in Polish). Clin Diabetol. 2015; 4(suppl A).

16. McLachlan K, Jenkins A, O'Neal D. The role of continuous glucose monitoring in clinical decision-making in diabetes in pregnancy. Aust N Z J Obstet Gynaecol. 2007; 47(3): 186-190, doi: 10.1111/j.1479-828X.2007.00716.x, indexed in Pubmed: 17550484.

17. Rosenn BM, Miodovnik M, Holcberg G, et al. Hypoglycemia: the price of intensive insulin therapy for pregnant women with insulin-dependent diabetes mellitus. Obstet Gynecol. 1995; 85(3): 417-422, doi: 10.1016/0029-7844(94)00415-A, indexed in Pubmed: 7862383.

18. Evers IM, ter Braak EW, de Valk HW, et al. Risk indicators predictive for severe hypoglycemia during the first trimester of type 1 diabetic pregnancy. Diabetes Care. 2002; 25(3): 554-559, doi: 10.2337/diacare.25.3.554, indexed in Pubmed: 11874946.

19. Nielsen LR, Pedersen-Bjergaard U, Thorsteinsson B, et al. Hypoglycemia in pregnant women with type 1 diabetes: predictors and role of metabolic control. Diabetes Care. 2008; 31(1): 9-14, doi: 10.2337/dc07-1066, indexed in Pubmed: 17909091.

20. Hellmuth E, Damm P, Mølsted-Pedersen L, et al. Prevalence of nocturnal hypoglycemia in first trimester of pregnancy in patients with insulin treated diabetes mellitus. Acta Obstet Gynecol Scand. 2000; 79(11): 958-962, doi: 10.3109/00016340009169242, indexed in Pubmed: 11081680.

21. ter Braak EW, Evers IM, Willem Erkelens D, et al. Maternal hypoglycemia during pregnancy in type 1 diabetes: maternal and fetal consequences. Diabetes Metab Res Rev. 2002; 18(2): 96-105, doi: 10.1002/dmrr.271, indexed in Pubmed: 11994900.

22. Bode BW, Steed RD, Davidson PC. Reduction in severe hypoglycemia with long-term continuous subcutaneous insulin infusion in type I diabetes. Diabetes Care. 1996; 19(4): 324-327, doi: 10.2337/diacare.19.4.324, indexed in Pubmed: 8729154.

23. Kallas-Koeman MM, Kong JM, Klinke JA, et al. Insulin pump use in pregnancy is associated with lower $\mathrm{HbA} 1 \mathrm{c}$ without increasing the rate of severe hypoglycaemia or diabetic ketoacidosis in women with type 1 diabetes. Diabetologia. 2014; 57(4): 681-689, doi: 10.1007/s00125-014-3163-6, indexed in Pubmed: 24434960.

24. Deiss D, Bolinder J, Riveline JP, et al. Improved glycemic control in poorly controlled patients with type 1 diabetes using real-time continuous glucose monitoring. Diabetes Care. 2006; 29(12): 2730-2732, doi: 10.2337/dc06-1134, indexed in Pubmed: 17130215.

25. Tamborlane WV, Beck RW, Bode BW, et al. Juvenile Diabetes Research Foundation Continuous Glucose Monitoring Study Group. Continuous glucose monitoring and intensive treatment of type 1 diabetes. N Engl J Med. 2008; 359(14): 1464-1476, doi: 10.1056/ /NEJMoa0805017, indexed in Pubmed: 18779236.

26. O'Connell MA, Donath S, O'Neal DN, et al. Glycaemic impact of patient-led use of sensor-guided pump therapy in type 1 diabetes: a randomised controlled trial. Diabetologia. 2009; 52(7): 1250-1257, doi: 10.1007/s00125-009-1365-0, indexed in Pubmed: 19396424.

27. Raccah D, Sulmont V, Reznik Y, et al. Incremental value of continuous glucose monitoring when starting pump therapy in patients with poorly controlled type 1 diabetes: the RealTrend study. Diabetes Care. 2009; 32(12): 2245-2250, doi: 10.2337/ /dc09-0750, indexed in Pubmed: 19767384.

28. Bergenstal RM, Tamborlane WV, Ahmann A, et al. STAR 3 Study Group. Effectiveness of sensor-augmented insulin-pump therapy in type 1 diabetes. N Engl J Med. 2010; 363(4): 311-320, doi: 10.1056/NEJMoa1002853, indexed in Pubmed: 20587585.

29. Hermanides J, Nørgaard K, Bruttomesso D, et al. Sensor-augmented pump therapy lowers $\mathrm{HbA}(1 \mathrm{c})$ in suboptimally controlled Type 1 diabetes; a randomized controlled trial. Diabet Med. 2011; 28(10): 1158-1167, doi: 10.1111/j.1464-5491.2011.03256.x, indexed in Pubmed: 21294770.

30. Battelino T, Conget I, Olsen B, et al. The SWITCH Study: Continuous glucose monitoring in type 1 diabetes. Pediatr Diabetes. 2011; 12(suppl 15): 14-39.

31. Nørgaard K, Scaramuzza A, Bratina N, et al. Interpret Study Group. Routine sensor-augmented pump therapy in type 1 diabetes: the INTERPRET study. Diabetes Technol Ther. 2013; 15(4): 273-280, doi: 10.1089/dia.2012.0288, indexed in Pubmed: 23438304.

32. Danne T, Kordonouri O, Holder M, et al. Prevention of hypoglycemia by using low glucose suspend function in sensor-augmented pump therapy. Diabetes Technol Ther. 2011; 13(11): 1129-1134, doi: 10.1089/dia.2011.0084, indexed in Pubmed: 21827318.

33. Garg S, Brazg RL, Bailey TS, et al. Reduction in duration of hypoglycemia by automatic suspension of insulin delivery: the in-clinic ASPIRE study. Diabetes Technol Ther. 2012; 14(3): 205-209, doi: 10.1089/dia.2011.0292, indexed in Pubmed: 22316089.

34. Halford J, Harris C. Determining clinical and psychological benefits and barriers with continuous glucose monitoring therapy. Diabetes Technol Ther. 2010; 12(3): 201-205, doi: 10.1089/ /dia.2009.0121, indexed in Pubmed: 20151770.

35. Gonder-Frederick L, Nyer M, Shepard JA, et al. Assessing fear of hypoglycemia in children with Type 1 diabetes and their parents. 
Diabetes Manag (Lond). 2011; 1(6): 627-639, doi: 10.2217/ /DMT.11.60, indexed in Pubmed: 22180760.

36. Murphy HR, Elleri D, Allen JM, et al. Pathophysiology of postprandial hyperglycaemia in women with type 1 diabetes during pregnancy. Diabetologia. 2012; 55(2): 282-293, doi: 10.1007/ /s00125-011-2363-6, indexed in Pubmed: 22080230.

37. Gupta R, Khoury J, Altaye M, et al. Glycemic Excursions in Type 1 Diabetes in Pregnancy: A Semiparametric Statistical Approach to Identify Sensitive Time Points during Gestation. J Diabetes Res. 2017; 2017: 2852913, doi: 10.1155/2017/2852913, indexed in Pubmed: 28280744.

38. Herranz L, Pallardo LF, Hillman N, et al. Maternal third trimester hyperglycaemic excursions predict large-for-gestational-age infants in type 1 diabetic pregnancy. Diabetes Res Clin Pract. 2007; 75(1): 42-46, doi: 10.1016/j.diabres.2006.05.019, indexed in Pubmed: 16837097.

39. Bradley C. The Diabetes Treatment Satisfaction Questionnaire: DTSQ. In: Bradley C. ed. Handbook of Psychology and Diabetes: A Guide to Psychological Measurement in Diabetes Research and Practice. Harwood Academic Publishers, Switzerland 1994: 111-133.

40. Bradley C. Diabetes treatment satisfaction questionnaire. Change version for use alongside status version provides appropriate solution where ceiling effects occur. Diabetes Care. 1999; 22(3): 530-532, doi: 10.2337/diacare.22.3.530, indexed in Pubmed: 10097946.

41. Murphy HR, Rayman G, Lewis K, et al. Effectiveness of continuous glucose monitoring in pregnant women with diabetes: ran- domised clinical trial. BMJ. 2008; 337: a1680, doi: 10.1136/bmj. a1680, indexed in Pubmed: 18818254.

42. Hayes M. CSII therapy in pregnancies complicated by type 1 diabetes: a review. J Diabetes Nurs. 2008; 12: 194-198.

43. Cyganek K, Hebda-Szydlo A, Katra B, et al. Glycemic control and selected pregnancy outcomes in type 1 diabetes women on continuous subcutaneous insulin infusion and multiple daily injections: the significance of pregnancy planning. Diabetes Technol Ther. 2010; 12(1): 41-47, doi: 10.1089/dia.2009.0081, indexed in Pubmed: 20082584.

44. Wender-Ozegowska E, Zawiejska A, Ozegowska K, et al. Multiple daily injections of insulin versus continuous subcutaneous insulin infusion for pregnant women with type 1 diabetes. Aust N Z J Obstet Gynaecol. 2013; 53(2): 130-135, doi: 10.1111/ajo.12027, indexed in Pubmed: 23316799.

45. Bruttomesso D, Bonomo M, Costa S, et al. Italian Group for Continuous Subcutaneous Insulin Infusion in Pregnancy. Type 1 diabetes control and pregnancy outcomes in women treated with continuous subcutaneous insulin infusion (CSII) or with insulin glargine and multiple daily injections of rapid-acting insulin analogues (glargine-MDI). Diabetes Metab. 2011; 37(5): 426-431, doi: 10.1016/j.diabet.2011.02.002, indexed in Pubmed: 21474360.

46. Mukhopadhyay A, Farrell T, Fraser RB, et al. Continuous subcutaneous insulin infusion vs intensive conventional insulin therapy in pregnant diabetic women: a systematic review and metaanalysis of randomized, controlled trials. Am J Obstet Gynecol. 2007; 197(5): 447-456, doi: 10.1016/j.ajog.2007.03.062, indexed in Pubmed: 17678864. 